\title{
Pharmacological treatment of the biochemical defect in cystic fibrosis airways
}

\author{
H.C. Rodgers, A.J. Knox
}

\begin{abstract}
Pharmacological treatment of the biochemical defect in cystic fibrosis airways. H.C. Rodgers, A.J. Knox. C ERS Journals Ltd 2001.

ABSTRACT: The understanding of the biochemical defect in cystic fibrosis (CF) has advanced considerably since discovery of the CF gene in 1989 and characterization of its product. Studies showing that the abnormality in chloride flux could be corrected by transfection of wild-type cystic fibrosis transmembrane conductance regulator (CFTR) complimentary deoxyribonucleic acid (cDNA) have led to gene therapy trials on both sides of the Atlantic. However, gene therapy as a treatment for CF has yet to be realized.

Pharmacological manipulation of the biochemical defect may provide an alternative or complementary approach to treatment. This review will discuss pharmacological agents in development which could correct the abnormal ion movement.

The mechanisms of action of these pharmacological agents can be divided broadly into drugs which affect the most common $C F$ mutation, $\triangle F 508$, which increase trafficking of the mutant $\mathrm{CF}$ protein to the apical membrane; drugs which increase chloride secretion; and drugs which reduce sodium reabsorption across the apical membrane.

Treatment options for cystic fibrosis have developed rapidly since discovery of the cystic fibrosis gene over a decade ago. The targeting of specific therapies for particular cystic fibrosis genotypes and the use of combination treatments of chloride channel openers with sodium channel blockers are likely to be key advances in the next decade. Eur Respir J 2001; 17: 1314-1321.
\end{abstract}

Respiratory Medicine Unit, City Hospital, Nottingham, UK.

Correspondence: A.J. Knox, Respiratory Medicine Unit, Clinical Sciences Building, City Hospital, Hucknall Road, Nottingham NG5 1PB UK Fax: 441158404771

Keywords: Amiloride

cystic fibrosis

ion transport

pharmacogenetics

trafficking

treatment

Received: October 22000

Accepted after revision January 10 2001

This study was supported by the UK Cystic Fibrosis Trust.
Cystic fibrosis (CF) is caused by mutations of the $\mathrm{CF}$ gene on chromosome 7 , which codes for the cystic fibrosis transmembrane conductance regulator protein (CFTR). CFTR is a cyclic adenosine monophosphate (cAMP) regulated chloride channel which regulates the epithelial sodium channel $(\mathrm{ENaC})$ and it may have other functions including the transport of adenosine triphosphate (ATP) [1]. More than $850 \mathrm{CF}$ mutations are currently recognized. These mutations cause defects in CFTR trafficking and/or activation leading to reduced epithelial chloride secretion by CFTR and excessive sodium absorption through $\mathrm{ENaC}$ [2]. The mechanism by which abnormal ion transport causes CF lung disease is controversial, with two theories predominating [3] (fig. 1). The isotonic volume depletion theory (figs. 1a and c) suggests that isotonic absorption of salt and water from the apical membrane in CF airway epithelium occurs as a result of increased ENaC activity [4]. This leads to volume depletion of the airway surface liquid (ASL), dehydration of the mucus layer and formation of "mucus plaques" which adhere to the airway epithelium leading to bacterial colonization. An alternative theory, the hypotonic salt hypothesis (figs. $1 \mathrm{~b}$ and d), suggests that the pathogenesis of CF lung disease is linked to the deactivation of cationic peptides such as $\beta$-defensins [5] which are produced by airway epithelium and function optimally in hypotonic solutions. In
$\mathrm{CF}$, the ASL is less hypotonic thereby impairing $\beta$-defensin function and promoting bacterial colonization. Currently there is increasing evidence to support the isotonic model [6] but both may play a role [3]; however, normalization of the ion transport defect is thought to be the key to a cure for CF lung disease.

\section{Strategies aimed at increasing chloride secretion}

A number of pharmacological agents have been studied that increase chloride secretion in vitro. Figure 2 and table 1 give an overview of the different agents and proposed mechanism of action as discussed later in the text.

Cystic fibrosis transmembrane conductance regulator protein trafficking

The most common $\mathrm{CF}$ mutation is $\Delta \mathrm{F} 508$, caused by a deletion of a phenylalanine residue at amino acid position 508. The resulting conformational change in CFTR makes it vulnerable to degradation within the endoplasmic reticulum (ER) [7]. Nascent polypeptides fail to reach the apical membrane, resulting in the absence of a functional response. Attempts to 
a)

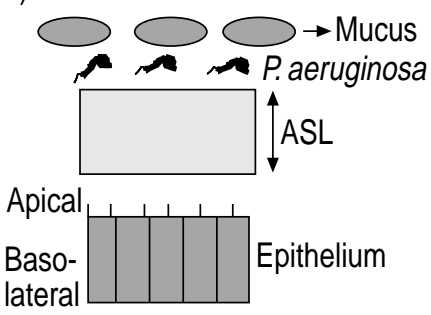

c)

Normal

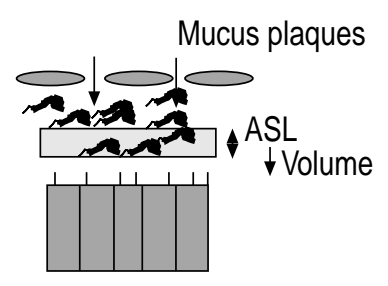

Cystic fibrosis b)

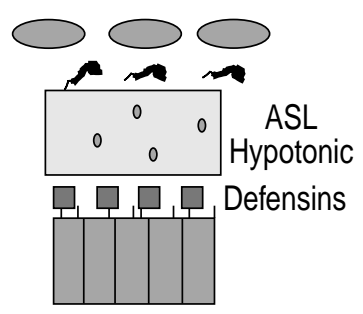

Normal

d)

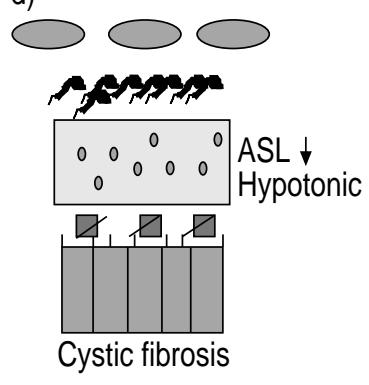

Fig. 1. - The Salt Hypotheses. ASL: airway surface liquid; $P$. aeuruginosa: Pseudomonas aeruginosa.

overcome the defect in the $\Delta \mathrm{F} 508$ mutation involve increasing CFTR trafficking.

\section{Chemical chaperones}

The observation that low temperature induced a proportion of cultured fibroblasts to show normal maturation of $\Delta$ F508-CFTR $[8,9]$ lead to the search for chemical entities with similar properties. The first

Table 1.-Proposed mechanisms for different pharmacological agents

Pharmacological Proposed mechanism agent

\begin{tabular}{|c|c|}
\hline $4 \mathrm{PBA}$ & $\begin{array}{l}\text { Increase in trafficking } \\
\text { Decrease in ubiquitination }\end{array}$ \\
\hline Glycerol & Increase in trafficking \\
\hline IBMX & $\begin{array}{l}\text { Phosphodiesterase inhibition } \\
\text { Direct activation CFTR }\end{array}$ \\
\hline Forskolin & Adenyl cyclase activation \\
\hline Milrinane & $\begin{array}{l}\text { Phosphodiesterase inhibition plus } \\
\text { adenyl cyclase activation }\end{array}$ \\
\hline Amrinone & $\begin{array}{l}\text { Phosphodiesterase inhibition plus } \\
\text { adenyl cyclase activation }\end{array}$ \\
\hline CPX & $\begin{array}{l}\text { Phosphodiesterase inhibition } \\
\text { Direct activation CFTR }\end{array}$ \\
\hline Genistein & $\begin{array}{l}\text { Tyrosine kinase activation } \\
\text { Protein phosphatase inhibition } \\
\text { Direct activation CFTR }\end{array}$ \\
\hline CNP & cGMP regulation of CFTR \\
\hline UTP, ATP & Activation of other chloride channels \\
\hline Calcium ATPase & Decrease in ubiquitination \\
\hline inhibitors & Calcium dependant involving CaMKII \\
\hline
\end{tabular}

4-PBA: sodium 4-phenylbutyrase; IBMX: 1-methyl-3-isobutylxanthine; CPX: 8-cyclo-pentyl-1,3-dipropylxanthine; CNP: C-type natriuretic peptide; UTP: uridine triphosphase; ATP: adenosine triphosphate; ATPase: adenosine triphosphatase; CFTR: cystic fibrosis transmembrane conductance regulator protein.

chemical chaperone to be studied was glycerol [9, 8], which increased expression of fully glycosylated $\Delta$ F508 protein at the plasma membrane of cultured mammary carcinoma cells [9]. However, an open parallel group study in CF subjects, using two doses of topical glycerol, showed no effect on nasal potential

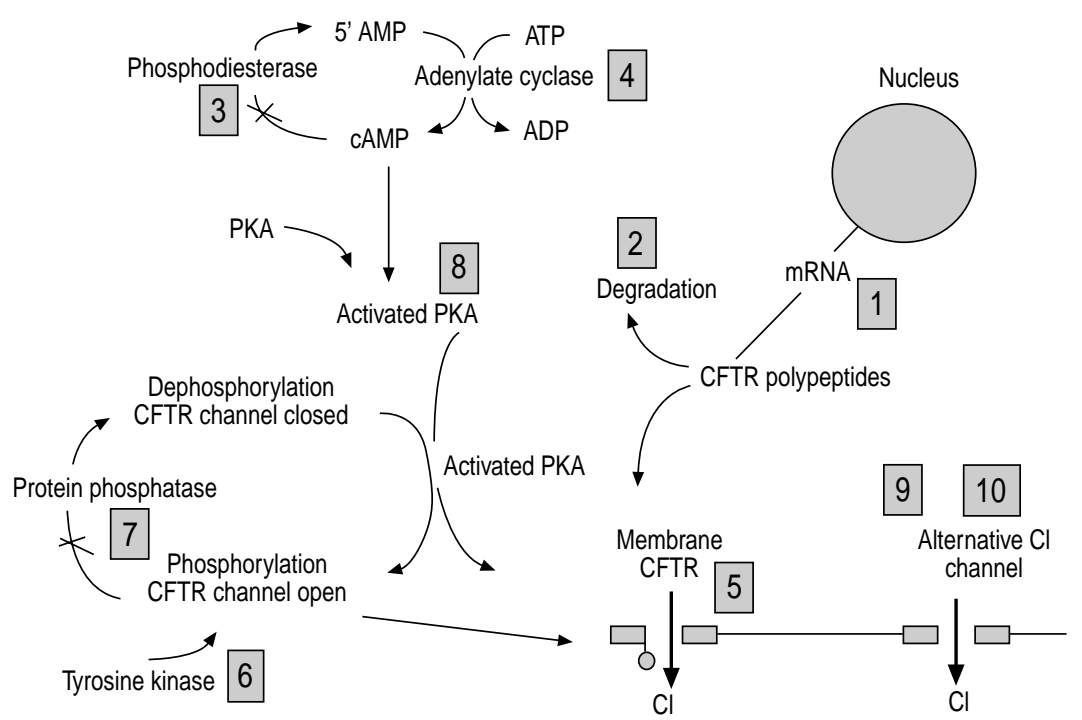

Fig. 2. - Potential targets for pharmacological manipulation of chloride channel activation. The mechanisms are indicated by the following numbers: 1: increase in trafficking; 2: decrease in ubiquitination; 3: phosphodiesterase inhibition; 4: adenyl cyclase activation; 5: direct activation of cystic fibrosis transmembrane conductance regulator (CFTR); 6: tyrosine kinase activation; 7: protein phosphatase inhibition; 8: cyclic adenosine monophosphate (cAMP) regulation of CFTR; 9: activation of other chloride channels; 10: calcium dependant involving CaMkII. AMP: adenosine monophosphate; ATP: adenosine triphosphate; ADP: adenosine diphosphate; PKA: protein kinase; mRNA: messenger ribonucleic acid. 
difference (NPD) in $11 \Delta$ F508 homozygotes [10], suggesting glycerol is unlikely to be clinically useful. Other compounds acting in a similar manner may prove more effective, such as Trimethylamine $\mathrm{N}$-oxide (TMAO), which increases chloride efflux in $\mathrm{CF}$ trachea epithelial (CFTEo) cells, a $\Delta$ F508 expressing cell line [10]. This area is likely to expand rapidly in the future.

\section{Sodium 4-phenylbutyrate}

Butyric acid and its analogues have been shown to upregulate CFTR-messenger ribonucleic acid (mRNA) in C127 cells expressing $\Delta$ F508 [11, 12]. Butyrate itself is short-acting and toxic, but its analogue, sodium 4-phenylbutyrate (4-PBA), shows more promise. Forskolin-induced chloride secretion in IB3-1 cells expressing $\Delta \mathrm{F} 508 / \mathrm{W} 1282 \mathrm{X}$, and in primary human nasal epithelium, was increased by 4-PBA [13]. Although these agents increase CFTR-mRNA expression, they may also have other actions. The ubiquitination protein Hsc70 in IB3-1 cells and human bronchial epithelial cells was downregulated by 4PBA. This would be expected to increase CFTR trafficking by reducing tagging of mutant protein for degradation, thereby allowing more $\Delta$ F508-CFTR protein to reach the apical membrane [14].

A pilot study of 4-PBA in cystic fibrosis patients in vivo showed partial restoration in nasal epithelia CFTR function in $18 \Delta \mathrm{F} 508$ patients treated for 1 week with oral 4-PBA or placebo (nine in each group) [15]. Longer term, larger studies of more potent 4-PBA analogues are needed.

\section{Treatments aimed at increasing chloride currents}

\section{Phosphodiesterase inhibitors}

Mutant forms of CFTR can be activated if stimulated with high levels of phosphodiesterase (PDE) inhibitors [16]. Xenopus oocytes injected with wild-type or mutant CFTR required five times as much xanthine 1-methyl-3-isobutyl-xanthine (IBMX), a nonselective PDE inhibitor, to stimulate chloride secretion, compared with wild-type. Stimulation only occurred in the presence of forskolin (an adenyl cyclase activator) [16]. However, results with IBMX have been conflicting. In normal and $\mathrm{CF}$ airway epithelium, high doses of IBMX and forskolin failed to increase chloride efflux, thus inhibiting chloride secretion in primary cultures from normal patients $[17,18]$

Another nonselective PDE inhibitor is 8-cyclopentyl-1, 3-dipropylxanthine (CPX). CPX increased chloride channel activation of CFPAC-1 or NIH 3T3 cells expressing $\triangle \mathrm{F} 508 \mathrm{CFTR}$, but not in cells expressing wild-type CFTR [19]. Similar results were seen in the human airway cell line IB3 derived from a $\Delta \mathrm{F} 508 / \mathrm{W} 1282 \mathrm{X} \mathrm{CF}$ patient [20]. In contrast, CPX alone had no effect on wild-type or mutant CFTR in mouse mammary epithelial cells (Ca127 cells), although it did potentiate the forskolin response in mutant cells [21].
PDE consists of a family of enzymes which differ in their selectivity for, and activation by, cAMP and cyclic guanosine monophosphate (cGMP). Whilst IBMX and CPX are nonselective PDE inhibitors, studies with cAMP selective PDE inhibitors have been more promising. Type III inhibitors, milrinone and amrinone, are more potent activators of chloride efflux in airway epithelial cells expressing wild-type CFTR than either IBMX or type IV (rolipram) inhibitors [22]. Milrinone and amrinone stimulated chloride efflux in wild-type Calu-3 and 16 human bronchial epithelial (HBE) cells without the addition of adenyl cyclase activators [23]. However, adenyl cyclase activation, in addition to milrinone, was required for stimulation of mutant CFTR (transformed CF nasal polyp cells expressing $\Delta \mathrm{F} 508 / \Delta \mathrm{F} 508$ ) or murine nasal epithelium in vivo $[18,22,23]$.

The mechanism of action of PDE inhibitors is contentious, as no correlation was found between the increases in cAMP and the degree of correction of chloride efflux in some studies [18, 21, 22]. This could reflect compartmentalization of PDE activity within epithelial cells, such that total cAMP levels do not reflect membrane cAMP [22]. Alternatively, non-PDE mechanisms may be involved including adenosine antagonism or a direct effect on CFTR. Adenosine antagonism seems unlikely because the potency of these agents as adenosine antagonists correlates poorly with CFTR opening [19, 20, 24]. A more attractive suggestion is that PDE inhibitors have a direct effect on CFTR through binding to the first nucleotide binding domain (NFB-1), the site of the $\Delta F 508$ mutation $[25,26]$. This hypothesis is supported by the rank order of potency for binding of different xanthines (DA-CPX $>$ DAX $>$ CPX $>$ caffeine $>$ adenosin $>$ IBMX) to NBF-1 which parallels the action of these compounds on chloride channel opening [26].

Data on the PDE inhibitors in vivo are limited. Topical milrinone had no effect on NPD in the presence of amiloride, isoprenaline or ATP in low chloride solution [27].

\section{Genistein}

Genistein, a tyrosine kinase inhibitor, increased CFTR channel activity in wild-type CFTR and in Hi5 insect cells which transiently express CFTR in the presence of forskolin [28]. The mechanism of action of genistein is unclear, but possibilities include tyrosine and protein phosphatase inhibition, direct interaction with the CFTR protein, or inhibition of topoisomerases [29, 30]. Genistein also stimulates sodium absorption in the human $\mathrm{CF}$ airway [31]. As genistein affects several cellular processes and its mechanism of action is unclear, it may not prove useful in $\mathrm{CF}$ therapy.

\section{Cyclic guanosine-3' 5'-monophosphate}

cGMP is produced by guanylate cyclases (GCs) which exist in soluble and particulate forms. Soluble GCs are activated by nitric oxide and related 
compounds, whereas particulate GCs are natriuretic peptide receptors. Both soluble and particulate GCs are abundant in airway epithelial cells [32]. cGMP has been shown to influence CFTR activity but the mechanism is unclear. Potential mechanisms include direct phosphorylation of CFTR by cGMP-dependant protein kinase (PKG), or by cGMP acting via phosphodiesterases which hydrolyse cAMP. In return, increased cAMP then activates cAMP-dependant protein kinases (PKAs) which phosphorylate CFTR.

Studies in Calu-3 cells, (which express high levels of CFTR) and CF-T43 cells (expressing $\Delta$ F508), showed that C-type natriuretic peptide (CNP), a ligand for type $\mathrm{C}$ particulate $\mathrm{GC}$, activated wild-type and mutant CFTR through PKA [33]. Cells expressing the CF mutant only showed activation when CNP was combined with isoprenaline, and wild-type cells showed a greater response than CF cells. CNP increased CFTR-dependant chloride efflux in $\mathrm{CF}$ mice in vivo [34] suggesting that studies with CNP in humans may be warranted.

\section{Triphosphate nucleotides}

The outwardly rectifying chloride channel (ORCC) is important in airway chloride secretion and is activated by CFTR [35]. PKA activation of CFTR causes ATP movement across the cell membrane. ATP then binds to $\mathrm{P}_{2}$ receptors, which activate ORCC. The mechanisms of ATP transport are unclear but may involve CFTR acting as a channel to directly transport ATP or by regulating ATP transport through an unidentified channel [1]. The defective regulation of ORCC in $\mathrm{CF}$ subjects can be overcome using topical ATP or uridine triphosphate (UTP) [36, 37]; however, longer acting $\mathrm{P}_{2} \mathrm{Y}_{2}$ receptor agonists are being evaluated. INS365 is safe in doses $\leq 100 \mathrm{mg}$ in healthy volunteers or in single doses $\leq 80 \mathrm{mg}$ in $\mathrm{CF}$ subjects, but data on efficacy are awaited [38]

\section{Calcium adenosine triphosphatase inhibitors}

A number of epithelial chloride channels are calcium dependent. Therefore, strategies which increase calcium release or reduce calcium re-uptake may be beneficial. Calcium adenosine triphosphatase (ATPase) inhibitors such as thapsigargin, cyclopiazonic acid and 2,5-di-(tert-butyl)-1,4-hydroquinone (DBHQ) inhibit $\mathrm{Ca}^{2+}$ re-uptake by intracellular stores and increase cytosolic free $\mathrm{Ca}^{2+}$. This may increase chloride secretion via a calcium-regulated chloride signalling pathway [1]. Alternatively, trafficking may increase by reducing the activity of calcium dependant proteins such as calnexin and uridine diphosphate (UDP) glucose: glycoprotein glycocyl transferase (UGGT), which are involved in retaining misfolded $\triangle F 508-C F T R$ in the ER. Preliminary data in CFPAC-1 cells showed that altering intraluminal ER calcium with thapsigargin allowed $\Delta F 508-C F T R$ to be released from the ER while functioning at the apical membrane [39]. Although calcium ATPase inhibitors could theoretically be of use in $\Delta F 508$, their toxicity is likely to preclude use in patients.

\section{Treatments for stop mutations}

\section{Aminoglycosides}

Aminoglycosides have been used to treat stop mutations, which are class 1 mutants with their premature termination of CFTR-mRNA translation producing truncated, nonfunctional CFTR. Although these are common amongst Ashkenazi Jews [40], they affect only a small percentage of $\mathrm{CF}$ patients worldwide [41]. Partial functional correction of two CF stop mutations was achieved in HeLa cells using the aminoglycoside G-418 [41]. Gentamicin and tobramicin had weaker effects but did not alter chloride channel activity. IB3 cells, heterozygous for W1282X treated with G418 or gentamicin, showed increased cAMP mediated current, although possibly via the ORCC rather than CFTR [42]. Beneficial changes in NPD were reported with topical gentamicin $(0.3 \%$ t.d.s) for 14 days in nine patients homozygous for stop mutations [43]. Larger randomized controlled trials are needed to confirm these findings.

\section{Strategies aimed at reducing sodium absorption}

An alternative or complementary approach is to target the increased sodium reabsorption. ENaC is responsible for the increased sodium absorption in $\mathrm{CF}$ airway epithelia as a result of abnormal regulation by defective CFTR. CFTR plays a central role in the regulation of $\mathrm{ENaC}$ and other ion channels. Figure 3 shows how these other ion channels are affected in $\mathrm{CF}$ and how they can be manipulated pharmacologically.

\section{Amiloride and its analogues}

Attempts to reduce sodium reabsorption in airway epithelium have concentrated on apical $\mathrm{ENaC}$ inhibitors. Amiloride inhibits several epithelial sodium transport processes including $\mathrm{ENaC}$ and is a potent inhibitor of sodium transport in vitro and in vivo [44, 45]. Although short-term topical amiloride administration blocks sodium transport across nasal epithelia in normal and CF subjects [46, 47], three placebocontrolled crossover studies of nebulized amiloride show conflicting results [48-50]. A 25-week North American study [48] showed a reduction in lung function decline in $18 \mathrm{CF}$ subjects, whereas a 6-month UK study showed no effect [49]. Lung function was unaffected when amiloride was added to inpatient treatment of pulmonary exacerbations in $27 \mathrm{CF}$ patients [50].

The lack of efficacy of amiloride in vivo may be due to its short duration of action [51, 52]. Amiloride is cleared rapidly from the airways and its effect on lower airway potential difference lasts for only $30 \mathrm{~min}$ [53]. Thus, even with repeated dosing, amiloride would only block sodium reabsorption for a short 
a)

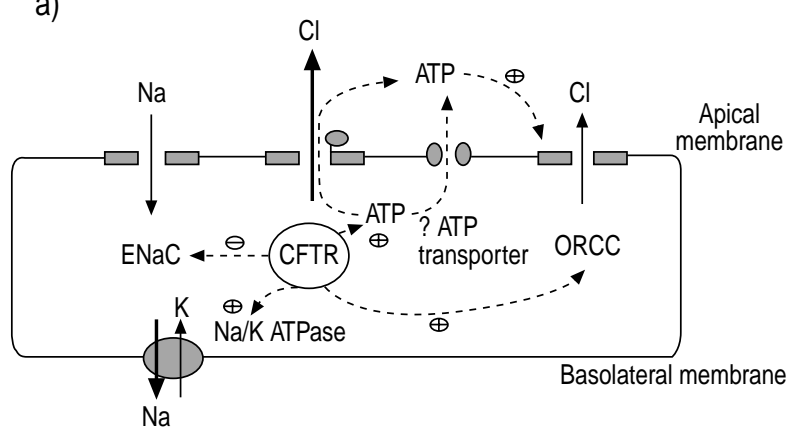

b)

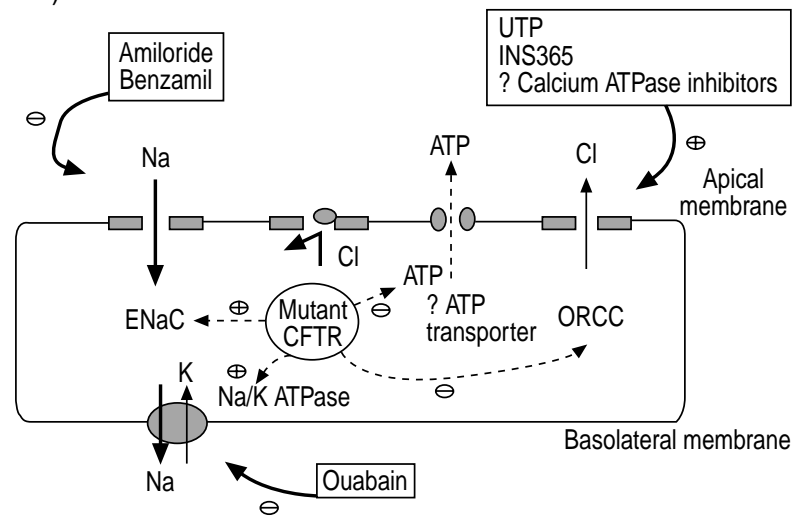

Fig. 3. - Cystic fibrosis (CF) transmembrane conductance regulator protein (CFTR) as a regulator of other channels. a) Normal airway epithelium; b) pharmacological correction in CF airway epthelium. ATP: adenosine triphosphate; ENaC: epithelial sodium channel; ORCC: outwardly rectifying chloride; ATPase: adenosine triphosphatase.

time [54]. Therefore, longer acting sodium channel blockers may prove more effective.

Benzamil, a benzyl substituted amiloride analogue, is a more potent and longer acting sodium channel inhibitor than amiloride in cultured human nasal epithelium [55]. Benzamil had a longer duration of action on NPD than amiloride in an open, parallel group study of $\mathrm{CF}$ subjects [56]. A randomized, placebo-controlled, crossover study in $10 \mathrm{CF}$ subjects showed similar results [57] with an 8-h duration of action. Although Benzamil is promising as a longacting sodium channel inhibitor, studies on its longterm efficacy and toxicity in the lung are required.

\section{Sodium/potassium-adenosine triphosphatase inhibitors}

Sodium absorption through the basolateral sodiumpotassium-adenosine triphosphatase $\left(\mathrm{Na}^{+} \mathrm{K}^{+}\right.$ATPase) is also increased in $\mathrm{CF}[58,59]$. The $\mathrm{Na}^{+} /$ $\mathrm{K}^{+}$-ATPase can be inhibited by cardiac glycosides such as ouabain and digoxin. Ouabain inhibits sodium reabsorption in intact epithelium strips in several species including man $[60,61]$ and intravenous ouabain reduces NPD in the dog in vivo [44]. However, two double-blind, placebo-controlled, crossover studies showed no effect on NPD for either topically applied ouabain or oral digoxin given to CF patients over 2 weeks [59]. This suggests that $\mathrm{Na}^{+} / \mathrm{K}^{+}$-ATPase inhibitors, at nontoxic doses, do not achieve sufficient inhibition of $\mathrm{Na}^{+} / \mathrm{K}^{+}$ATPase to be of therapeutic use.

\section{Loperamide}

Loperamide, an opiod receptor agonist, inhibited sodium ion flux in the rat small bowel in vitro [62]. Although loperamide reduced NPD in CF mouse nasal epithelium in vivo [63], preliminary data in humans show that loperamide is less potent than amiloride in inhibiting NPD in CF suggesting that it is unlikely to be clinically useful [64].

\section{Treatment combinations}

Combining a sodium channel blocker with a chloride channel opener, thus mimicking normal conditions, seems an attractive option for the treatment of CF. To date, there is little data in vivo on this approach. A murine study showed dose-dependent NPD changes with UTP and amiloride, which suggests chloride secretion [65]. A preliminary report [66] showed an improvement in mucociliary clearance (MCC) after short-term treatment with aerosolized UTP and amiloride in $12 \mathrm{CF}$ and 10 normal subjects. Future studies are likely to investigate combinations of chloride channel openers and sodium channel blockers as well as combinations of chloride channel openers which involve different pathways (e.g. trafficking compounds combined with drugs which directly activate CFTR).

\section{Pharmacogenetics}

Although the study of pharmacogenetics is in its infancy, it may have a role in cystic fibrosis. Genetic factors which potentially play a role in determining treatment responses in diseases such as asthma have been identified, although the clinical application of such technology has yet to be developed [67]. In CF, determination of the CF genotype has been available for many years and has mainly been used for diagnostic purposes. However, the application of genotyping in order to determine pharmacological treatment is an exciting concept. The major role of pharmacogenetics in CF is likely to be in the development of drugs targeting $\Delta \mathrm{F} 508$, the mutation most commonly seen in the CF population. The recent development of high throughput screening provides rapid, repeatable assays capable of detecting cell chloride permeability [68]. This technology will be used to rapidly screen libraries of compounds in order to detect potential trafficking drugs of the future, and will have great impact on the efficacy of such drugs as well as their speed of development. Pharmacogenetics will also have an impact on other CF mutations such as the use of aminoglycosides for stop mutations, particularly in geographical areas where such geneotypes 
are common. However the use of pharmacogenetics for other $\mathrm{CF}$ genotypes may be limited on pharmacoeconomic grounds.

\section{Conclusions}

There are a number of pharmacological agents in development aimed at correcting the electrophysiological defect seen in $\mathrm{CF}$ airways. These agents are likely to become increasingly specific, targeting patients with particular genotypes. Clinical trials have incorporated 4-PBA, probably the most advanced chloride secretagogue in development. It has the advantage of being effective as a single agent, unlike the PDE inhibitors which require concomitant treatment with adenyl cyclase activators $[16,19,30]$. However, 4-PBA and other trafficking drugs appear to increase amiloride sensitive sodium transport [11, 23]. Similarly, studies of UTP and gene therapy have shown that although these approaches produce a degree of correction of the chloride current, they do not correct sodium reabsorption $[15,36,69]$. This suggests that there may be added benefit in giving these agents in combination with sodium channel blockers. Although clinical studies with amiloride have been disappointing [48, $49,50]$ the use of longer acting sodium channel blockers, such as benzamil, may prove more beneficial.

Pharmacological treatments to correct the ion transport defect in cystic fibrosis have emerged over the last decade with expanding knowledge of the structure and function of cystic fibrosis transmembrane conductance regulator. Perhaps the combination of drugs that correct different aspects of cystic fibrosis transmembrane conductance regulator function will be the way forward in the next decade.

\section{References}

1. Schwiebert EM, Benos DJ, Egan ME, Jackson M, Stutts MJ, Guggino WB. CFTR is a conductance regulator as well as a chloride channel. Physiol Rev 1999; 79: S145-S166.

2. Stutts MJ, Canessa CM, Olsen JC, et al. CFTR as a cAMP - dependant regulator of sodium channels. Science 1995; 269: 847-850.

3. Guggino WB. Cystic fibrosis the salt controversy. Cell 1999; 96: 607-610.

4. Matsui H, Grubb BR, Tarran R, et al. Evidence for periciliary liquid layer depletion, not abnormal ion composition, in the pathogenesis of cystic fibrosis airway disease. Cell 1998; 95: 1005-1015.

5. Smith JJ, Travis SM, Greenberg EP, Welsh MJ. Cystic fibrosis airway epithelia fail to kill bacteria because of abnormal airway surface fluid. Cell 1996; 85: $229-$ 236.

6. Matsui H, Davis CW, Tarran R, Boucher RC. Osmotic water permeabilities of cultured, well differentiated normal and cystic fibrosis airway epithelia. $J$ Clin Invest 2000; 105: 1419-1427.

7. Cheng SH, Gregory RJ, Marshall J, et al. Defective intracellular transport and processing of CFTR is the molecular basis of most cystic fibrosis. Cell 1990; 63: $827-834$.

8. Brown CR, Hong-Brown LQ, Biwersi J, Verkman AS, Welch WJ. Chemical chaperones correct the mutant phenotype of the $\Delta \mathrm{F} 508$ cystic fibrosis conductance regulator protein. Cell Stress Chaperones 1996; 1: $117-125$.

9. Sato S, Ward CL, Krouse ME, Wine JJ, Kopito RR. Glycerol reverses the mis-folding phenotype of the most common cystic fibrosis mutation. $J$ Biol Chem 1996; 2: $635-638$.

10. Chadwick S, Browning JE, Stern M, et al. Nasal application of Glycerol in $\Delta \mathrm{F} 508$ cystic fibrosis patients. Thorax 1998; 53: A60.

11. Cheng SH, Fang SL, Zabner J, et al. Functional activation of the cystic fibrosis trafficking mutant $\Delta$ F508-CFTR by over-expression. Am J Physiol 1995; 268: L615-L624.

12. Hyde SC, Smyth SE, Gruenert DC, Gill DR. The effects of 4-phenylbutyric acid on CFTR mRNA levels. Pediatr Pulmonol 1998; 17: 211.

13. Rubenstein RC, Egan ME, Zeitlin PL. In vitro pharmacologic restoration of CFTR-mediated chloride transport with sodium 4-phenylbutyrate in cystic fibrosis epithelial cells. J Clin Invest 1997; 100: 2457 2465.

14. Rubenstein RC, Zeitlin PL. Sodium 4-phenylbutyrate down regulates Hsc 70: implications for intracellular trafficking of $\Delta$ F508-CFTR. Am J Physiol 2000; 278: C259-C267.

15. Rubenstein RC, Zeitlin PL. A pilot clinical trial of oral sodium 4-Phenylbutyrate (Buphenyl) in $\Delta \mathrm{F} 508$ Homozygous cystic fibrosis patients. Am J Respir Crit Care Med 1998; 157: 484-490.

16. Drumm ML, Wilkinson DJ, Smit LS, et al. Chloride conductance expressed by $\Delta \mathrm{F} 508$ and other mutant CFTRs in xenopus oocytes. Science 1991; 254: $1797-$ 1799.

17. Boucher RC, Cotton CU, Gatzy JT. Evidence for reduced $\mathrm{Cl}$ and increased $\mathrm{Na}$ permeability in cystic fibrosis human primary cell cultures. J Physiol 1988; 405: $77-103$.

18. Kelley TJ, Al-Nakkash L, Cotton CU, Drumm ML. Activation of endogenous $\Delta \mathrm{F} 508$ cystic fibrosis transmembrane conductance regulator by phosphodiesterase inhibition. J Clin Invest 1996; 98: 513-520.

19. Eidelman O, Guay-Broder C, Van Galen PJM, et al. A1 adenosine - receptor antagonists activate chloride efflux from cystic fibrosis cells. Proc Natl Acad Sci USA 1992; 89: 5562 - 5566.

20. Guay-Broder C, Jacobson KA, Barnoy S, et al. A1 receptor antagonist 8-Cyclopentyl-1,3-dipropylxanthine selectively activates chloride efflux from human epithelial and mouse fibroblast cell lines expressing the cystic fibrosis transmembrane regulator $\Delta$ F508 mutation. Biochem 1998; 34: 9079-9087.

21. Haws CM, Nepomuceno IB, Krouse ME, et al. Delta F508-CFTR channels: Kinetics, activation by forskolin, and potentiation by xanthines. Am J Physiol 1996; 270: C1544-C1555.

22. Kelley TJ, Al-Nakkash L, Drumm ML. CFTRmediated chloride permeability is regulated by type III phosphodiesterases in airway epithelial cells. Am J Respir Cell Mol Biol 1995; 13: 657-664.

23. Kelley TJ, Thomas K, Milgram LJH, Drumm ML. In vivo activation of the cystic fibrosis transmembrane conductance regulator mutant $\Delta \mathrm{F} 508$ in murine nasal 
epithelium. Proc Nat Acad Sci USA 1997; 94: 2604 2608.

24. Chappe V, Mettey Y, Vierfond JM, et al. Structural basis for specificity and potency of xanthinederivatives as activators of the CFTR chloride channel. $\mathrm{Br}$ J Pharmacol 1998; 123: 683-693.

25. Logan J, Hiestand D, Huang Z, Muccio D, Haley B, Sorscher EJ. 3-Isobutyl-1-methylxanthine (IBMX) blocks binding of ATP analogues to the CFTR first nucleotide binding domain (NBD-1). FASEB J 1993; 7: A426.

26. Cohen BE, Lee G, Jacobson KA, et al. 8-Cyclopentl1,3-dipropylxanthine and other xanthines differentially bind to the wild type and $\Delta \mathrm{F} 508$ mutant first Nucleotide binding fold (NBF-1) domains of the cystic fibrosis transmembrane conductance regulator. Biochemistry 1997; 36: 6455-6461.

27. Knowles MR, Church NL, Waltner WE, Gatzy JT, Boucher RC. Amiloride in cystic fibrosis: safety, pharmacokinetics, and efficacy in the treatment of pulmonary disease. In: Cragoe EJ, Kleyman TR, Simchowitz L, eds. Amiloride and its analogs unique cation transport inhibitors. New York, VCH, 1992; pp. $301-316$.

28. Hwang TC, Yang IC, Reenstra WW. Genistein potentiated wild-type and $\Delta \mathrm{F} 508$ channel activity. Am J Physiol 1997; 273: C988-C998.

29. Weinreich F, Wood PG, Riordan JR, Nagel G. Direct action of genistein on CFTR. Pflugers Arch 1997; 434: $484-491$.

30. Illek B, Fischer H, Santos GF, Widdicombe JH, Machen TE, Reenstra WW. cAMP-independent activation of CFTR $\mathrm{Cl}$ channels by the tyrosine kinase inhibitor genistein. Am J Physiol 1995; 268: C886C893.

31. Devor DC, Pilewski JM. Effect of 1-EBIO, NS004, and Genistein on ion transport across human bronchial epithelium expressing wild-type and $\Delta \mathrm{F} 508$ CFTR. Pediatr Pulmonol 1998; 17: 219.

32. Range SP, Holland ED, Baston GP, Knox AJ. Regulation of guanosine 3'5'-cyclic monophosphate in ovine tracheal epithelial cells. Br J Pharmacol 1997; 120: $1249-1254$.

33. Kelley TJ, Al-Nakkash L, Drumm ML. C-type natriuretic peptide increases chloride permeability in normal and cystic fibrosis airway cells. Am J Respir Cell Mol Biol 1997; 16: 464-470.

34. Kelley TJ, Cotton CU, Drumm ML. In vivo activation of CFTR-dependent chloride transport in murine airway epithelium by CNP. Am J Physiol: 1997: L1065 - L1072.

35. Xia Y, Haws CM, Wine JJ. Disruption of monolayer integrity enables activation of a cystic fibrosis "bypass" channel in human epithelia. Nat Med 1997; 3: $802-$ 805.

36. Knowles MR, Clarke LL, Boucher RC. Activation by extracellular nucleotides of chloride secretion in the airway epithelia of patients with cystic fibrosis. $N \mathrm{Engl}$ J Med 1991; 325: 533 - 538.

37. Knowles MR, Clarke LL, Boucher RC. Extracellular ATP and UTP induce chloride secretion in nasal epithelia of cystic fibrosis patients and normal subjects in vivo. Chest 1992; 101: Suppl. 3. 60S-63S.

38. Noone PG, Accurso FJ, Aitkin ML, et al. Safety of aerosolized IN365 in patients with mild to moderate CF: results of a multi-centre therapeutic development network. Pediatr Pulmonol 1999; 19: 244.
39. Egan ME, Cahill PA, Ambrose CA, Pappoe L, Giebel JP, Caplan M. Small molecule approach to increasing $\triangle$ F508-CFTR surface expression in CF epithelial cells. Pediatr Pulmonol 2000; 19: 242.

40. Shoshani T. Association of a nonsense mutation (W1282X), the most common mutation in the Ashkenazi Jewish cystic fibrosis patients in Israel, with the presentation of severe disease. Am J Hum Genet 1992; 50: 222 - 228.

41. Howard M, Frizzell RA, Bedwell DM. Aminoglycoside antibiotics restore CFTR function by overcoming premature stop mutations. Nat Medicine 1996; 2: 467-469.

42. Bedwell DM, Kaenjak A, Benos DJ, et al. Suppression of a CFTR premature stop mutation in a bronchial epithelial cell line. Nat Medicine 1997; 3: 1280-1284.

43. Wilschanski M, Famini C, Blau C, et al. A pilot study of the effect of gentamicin on nasal potential difference measurments in cystic fibrosis patients carrying stop mutations. Am J Respir Crit Care Med 2000; 161: $860-865$.

44. Willumsen NJ, Boucher RC. Transcellular sodium transport in cultured cystic fibrosis human nasal epithelium. Am J Physiol 1991; 261: C332-C341.

45. Alton EWFW, Rogers DF, Logan-Sinclair R, Yacoub MH, Barnes PJ, Geddes DM. Bioelectric properties of cystic fibrosis airway obtained at heart lung transplantation. Thorax 1992; 47: 1010-1014.

46. Knowles MR, Gatzy JT, Boucher RC. Increased bioelectric potential difference across respiratory epithelia in cystic fibrosis. $N$ Engl J Med 1981; 305: $1489-1495$.

47. Boucher RC, Stutts MJ, Cantley L, Gatzy JT, Knowles MR. $\mathrm{Na}^{+}$transport in cystic fibrosis respiratory epithelia: abnormal basal rate and response to adenylate cyclase activation. $J$ Clin Invest 1986; 78: $1245-1252$.

48. Knowles MR, Church NL, Waltner WE, Yankakas JR, Gilligan P. A pilot study of aerosolized amiloride for the treatment of lung disease in cystic fibrosis. $N$ Engl J Med 1990; 322: 1189-1194.

49. Graham A, Hasani A, Alton EWFW, et al. No added benefit from nebulized amiloride in patients with cystic fibrosis. Eur Respir J 1993; 6: 1243 - 1248.

50. Bowler IM, Kelman B, Worthinton D, et al. Nebulised amiloride in respiratory exacerbations of cystic fibrosis: a randomised controlled trial. Arch Dis Child 1995; 73: 427-430.

51. Mentz WM, Brown JB, Friedman M, Stutts MJ, Gatzy JT, Boucher RC. Deposition, clearance and effects of aerosolized amiloride in sheep airways. $\mathrm{Am}$ Rev Respir Dis 1986; 134: 938 - 943.

52. App EM, King M, Helfesrieder R, Kohler D, Matthys $\mathrm{H}$. Acute and long-term amiloride inhalation in cystic fibrosis lung disease. Am Rev Respir Dis 1990; 141: $605-612$.

53. Waltner WE, Church NL, Gatzy JT, Boucher RC, Knowles MR. Deposition, pharmacokinetics and toxicity of amiloride aerosol in normal and cystic fibrosis subjects. Am Rev Respir Dis 1987; 135: A288.

54. Knowles MR, Church NL, Waltner WE, et al. Aerosolized amiloride as a treatment of cystic fibrosis lung disease: a pilot study. Adv Exp Med Biol 1991; 290: $119-132$.

55. Blank U, Clauss W, Weber WM. Effects of benzamil on human cystic fibrosis airway epithelium. Cell Physiol Biochem 1995; 5: 385-390. 
56. Hofmann T, Stutts MJ, Ziersch A, et al. Effects of topically delivered benzamil and amiloride on nasal potential difference in cystic fibrosis. Am J Respir Crit Care Med 1998; 157: $1844-1849$.

57. Rodgers HC, Knox AJ. The effect of topical benzamil and amiloride on nasal potential difference in cystic fibrosis. Eur Respir J 1999; 14: 693-696.

58. Stutts MJ, Knowles MR, Gatzy JT, Boucher RC. Oxygen consumption and oubain binding sites in cystic fibrosis nasal epithelium. Pediatr Res 1986; 20 : $1316-1320$.

59. Peckham DG, Conn A, Chotai C, Lewis S, Knox AJ. Effect of oral digoxin, topical ouabain and salbutamol on trans-epithelial nasal potential difference in patients with cystic fibrosis. Clin Sci 1995; 89: $277-$ 284.

60. Smith TW. Digitalis: mechanisms of action and clinical use. N Engl J Med 1988; 318: 358 -365.

61. Widdicombe JH, Ueki IF, Bruderman II, Nadel JA. The effect of sodium substitution and ouabain on ion transport by dog tracheal epithelium. Am Rev Respir Dis 1979; 120: 385-392.

62. Hardcastle J, Hardcastle PT, Cookson J. Inhibitory actions of loperamide on absortive processes in rat small intestine. Gut 1986; 27: 686-694.

63. Ghosal S, Taylor CJ, McGaw J. Modification of nasal membrane potential difference with inhaled amiloride and loperamide in the cystic fibrosis (CF) mouse. Thorax 1996; 51: 1229-1232.

64. Hofmann T, Noone PG, Robinson JM, Foy CE, Lindermann H, Knowles MR. Effect of loperamide perfusion on nasal trans-epithelial $\mathrm{PD}$ of $\mathrm{CF}$ patients in vivo. Am J Respir Crit Care Med 1996; 153: A779.

65. Ghosal S, Taylor CJ, Colledge WH, Ratcliff R, Evans MJ. Sodium channel blockers and uridine triphosphate: effects on nasal potential difference in cystic fibrosis mice. Eur Respir J 2000; 15: 146-150.

66. Bennett WD, Olivier KN, Zeman KL, Hohneker KH, Boucher RC, Knowles MR. Acute effect of aerosolised uridine $5^{\prime}$-triphosphate (UTP) + amiloride on mucociliary clearance in cystic fibrosis. Am J Respir Crit Care Med 1996; 153: 1796-1801.

67. Hall IP. Pharmacogenetics of asthma. Eur Respir $J$ 2000; 15: 449-451.

68. Jayaraman S, Haggie P, Wachter RM, Remington SJ, Verkman AS. Mechanism and cellular applications of green fluorescent protein-based halide sensor. $J$ Biol Chem 2000; 275: 6047-6050.

69. Caplan NJ, Alton EWFW, Middleton PG, et al. Liposome-mediated CFTR gene transfer to the nasal epithelium of patients with cystic fibrosis. Nat Med 1995; $1: 39-46$. 